\title{
REALIDADE DA MULHER PRESA NO RIO GRANDE DO NORTE
}

\section{Dr. Rafael Figueiró}

Vinculado à Universidade Potiguar. Possui Mestrado Profissional em Psicologia Organizacional e do Trabalho e faz parte do Grupo de Pesquisa Subjetividade e Movimentos Sociais. E-mail: figueiroz@hotmail.com

\section{Helba Melo}

Vinculada à Universidade Potiguar. E-mail: helbamidiam@outlook.com

\section{Vanessa Martins}

Vinculada à Universidade Potiguar. E-mail: vanessamslsilva@gmail.com

\section{RESUMO}

As políticas públicas voltadas para o encarceramento feminino são frágeis e pouco vistas na prática. Diante disso, teve-se o intuito de investigar a realidade das mulheres presas no estado do Rio Grande do Norte. Para tanto, foi delineado seu perfil social e penal, as condições de saúde a que estão submetidas e os aspectos jurídicos. Utilizou-se como amostra para essa pesquisa as mulheres que se encontram sob custódia em uma penitenciaria do Estado, aplicando um questionário com estas. Participaram quarenta e três mulheres, a maioria adultas jovens, pardas, solteiras, que estudaram até o ensino fundamental, trabalhavam antes do aprisionamento e recebiam baixa remuneração. A maior parte já foi julgada, não era reincidente e recebia assistência jurídica, prevalecendo o crime de tráfico de drogas. Além disso, as entrevistadas relataram não haver atendimento médico, odontológico, ginecológico e psiquiátrico. 0 único cuidado com a saúde consiste na realização de preventivos por uma enfermeira.

PALAVRAS-CHAVE: Mulher presa. Saúde mental. Lei de drogas. 


\section{INTRODUÇÃO}

O Departamento Penitenciário Nacional (DEPEN) aponta no relatório do Levantamento Nacional de Informações Penitenciárias (Infopen), de Junho de 2014 que, pela primeira vez, a população carcerária brasileira ultrapassa a marca de 600.000 pessoas, sendo 579.781 custodiadas no Sistema Penitenciário e 27.950 custodiadas pelas Secretarias de Segurança Pública em carceragens de delegacias ou estabelecimentos similares. Dessas, 7.081 estão distribuídas entre as 32 unidades prisionais do estado do Rio Grande do Norte (RN). Estas unidades são constituídas por Centros de Detenção Provisória, Cadeias Públicas, Penitenciárias Estaduais, Complexos Penais, além de uma Unidade Psiquiátrica. Todas essas unidades são geridas pela Secretaria de Estado da Justiça e Cidadania (SEJUC).

A partir da necessidade de assegurar os direitos dessa população, no ano de 1984 foi criada a Lei de Execução Penal (Lei no $\left.{ }^{\circ} 210\right)$ que prevê, entre outros direitos, a garantia à assistência material, à saúde, jurídica e educacional de pessoas privadas de liberdade.

No que concerne à assistência material, está compreendido que a unidade prisional é responsável pelo fornecimento de alimentação e vestuário, também deve dispor de instalações higiênicas e serviços que atendam às necessidades pessoais dos presos. Consta também a necessidade de um local que seja destinado a venda de produtos e objetos permitidos, mas que não são fornecidos pela Administração.

Sobre a assistência à saúde, a Lei define que esta deve ter caráter preventivo e curativo, através de atendimento médico, odontológico e farmacêutico, sendo que, quando o estabelecimento penal não oferecer essa estrutura de acesso à saúde, este serviço deverá ser prestado em outro local, mediante autorização da direção. Em relação a mulher presa, esta deve ter assegurado o acompanhamento médico, especialmente no pré-natal e no pós-parto.

Quanto a assistência jurídica, é previsto que os presos e os internados que não tenham recursos financeiros para constituir advogado, devem receber assistência integral e gratuita, pela Defensoria Pública, dentro e fora dos estabelecimentos penais. Além disso, é preciso que haja um local apropriado para o atendimento realizado pelo Defensor Público.

Levando estes dados em consideração e o fato de que o ambiente prisional por si só é propulsor de adoecimentos físicos e psíquicos (SANTA RITA, 2007), neste trabalho teve-se a intenção de caracterizar o encarceramento feminino no estado do $\mathrm{RN}$, para isto, guiou-se em três eixos, sendo eles: a oferta de serviços de saúde para essas mulheres, como acontecem e com que frequência; a existência e qualidade do suporte sócio familiar e a assistência 
jurídica, abarcando o motivo da prisão, se já foram julgadas e como são ofertados esses serviços.

\subsection{PROCEDIMENTOS, SUJEITOS E INSTRUMENTOS}

Para o delineamento da realidade da mulher presa no Rio Grande do Norte, foi tomado como amostra as mulheres que se encontravam encarceradas em uma penitenciaria estadual. Foi apresentada a proposta da pesquisa às presas, cela por cela, as que concordaram em participar assinaram um termo de consentimento e responderam a uma entrevista semiestruturada.

Aquele momento, encontravam-se na unidade feminina do Complexo Penal Dr. João Chaves cento e vinte e nove detentas, quarenta e três se dispuseram a colaborar com a pesquisa respondendo a entrevista. Nesta, foram abordadas questões para delinear o perfil social, entre elas, cor da pele, estado civil, escolaridade, idade, ocupação antes da prisão e renda familiar; questões sobre os aspectos sócio familiares como o número de filhos, onde e com quem estão durante o aprisionamento da mãe, se recebem visita e com que frequência; questões sobre o aspecto jurídico como o tipo de delito cometido, se já houve julgamento, como se dá a assistência jurídica que recebem e questões do aspecto de saúde como atendimento médico e odontológico.

\section{CONSIDERAÇÕES SOBRE O SISTEMA PENITENCIÁRIO FEMININO}

Desde o final do século XVIII vivemos numa "sociedade disciplinar", esse tipo de sociedade teve seu surgimento na reorganização do sistema judiciário e penal de diferentes países da Europa e do mundo (FOUCAULT, 2002). Beccaria, Benthan, Brissot e até mesmo Rosseau defendem que o criminoso é aquele que altera a ordem social, que perturba a sociedade, que rompe com as leis impostas e por isso precisa ser punido, sendo a punição caracterizada pela reparação ao dano causado (idem). Daí surgem quatro formas de punir: expulsar o criminoso da sociedade em que a lei está vigente; exclusão dentro do espaço social, sob a forma de exposição a fim de causar vergonha e humilhação ao criminoso; reparação do dano através do trabalho forçado numa atividade que beneficie a sociedade que sofreu com o crime cometido e a pena de talião, amplamente conhecida como "olho por olho, dente por 
dente" , com o intento de causar, no indivíduo que gerou um dano para a sociedade, repulsa pelo que fez (idem). No início do século XIX essas formas de punir desapareceram rapidamente da sociedade, sendo substituídas pela prisão, pelo aprisionamento dos criminosos (idem).

Levantamos a hipótese de que, ainda nos dias de hoje, o aprisionamento não tem caráter corretivo e sim punitivo e que, apesar da existência da Lei de Execução Penal, a administração pública se recusa a respeitar os direitos dos presos, reproduzindo e alimentando um sentimento arcaico de que "o bandido merece sofrer". É visível o desejo de punição da sociedade e do Estado quando nos deparamos com as condições do sistema penitenciário no Brasil. Wacquant (2001, p.09) descreve bem essas condições, ao dizer que:

\footnotetext{
O estado apavorante das prisões do país, que se parecem mais com campos de concentração para pobres, ou com empresas públicas de depósito industrial dos dejetos sociais, do que com instituições judiciárias servindo para alguma função penalógica - dissuasão, neutralização ou reinserção. O sistema penitenciário brasileiro acumula, com efeito, as taras das piores jaulas do Terceiro Mundo, mas levadas a uma escala digna do Primeiro Mundo, por sua dimensão e pela indiferença estudada dos políticos públicos.
}

No que se refere à questão do encarceramento feminino, antigamente, existia um posicionamento de separar, isolar as mulheres criminosas em estabelecimentos penais para uma "purificação" delas através de preceitos morais e religiosos, sendo essa uma visão clara de discriminação de gênero. Assim, ainda hoje, a punição se dá em dose dupla, por ser criminosa e mulher, pois além da punição sobre a infração, recai também sobre ela a discriminação de gênero e a punição moral, vinda da representação social do papel feminino, que determina à mulher o lugar doméstico, dócil, frágil, de cuidadora do lar e da família (Rita, 2007).

A prisão, caracterizada por ser uma instituição total, impõe aos sujeitos que nela estão um processo de "mortificação do eu" (GOFFMAN, 1974, p.24), que seria uma série de mutilações do eu com o intuito de adaptar, padronizar e dominar os sujeitos para a vida na instituição. Podemos citar o afastamento do convívio social e familiar; ruptura de papéis sociais, sendo algumas delas irreversíveis; a perda da identidade ao terem seus nomes trocados por números; desfiguração da sua imagem usual; impedimento de utilizar suas próprias vestimentas, sendo obrigadas em algumas unidades a utilizar uniformes que foram pensados para vestir corpos masculinos; exposição física; perda dos momentos de intimidade e de seus objetos pessoais; controle sobre suas atividades e submissão a procedimentos humilhantes. 
Na unidade visitada foi possível evidenciar as questões que Goffman trata como "mortificação do eu", as mulheres utilizam uniformes, não tem acesso a produtos de beleza, como maquiagens, esmaltes, bijuterias e acessórios de cabelos, assim como também não tem acesso a roupas próprias e algumas peças íntimas. Além disso, elas relatam episódios humilhantes durante as revistas e isolamento numa cela escura e suja que é destinada ao castigo.

Além das más condições que os presos de uma maneira geral precisam enfrentar, as mulheres enfrentam um problema à parte, os presídios normalmente não são construídos pensando em atender mulheres e sim homens. A Lei de Execução Penal prevê que os estabelecimentos prisionais sejam separados em masculino e feminino, para que assim possam ser implementadas políticas públicas específicas para cada gênero. Apesar disso, no Brasil, 75\% dos estabelecimentos prisionais são masculinos, 17\% são masculinos com alas femininas (unidades mistas) e apenas $7 \%$ são femininos. Concluindo-se que a maioria das mulheres encontra-se custodiada em unidades mistas, o que dificulta a implementação de políticas específicas para elas (DEPEN, 2014). Aliás, muitas vezes prédios públicos que foram considerados inadequados, sejam por questões de estrutura, de insalubridade ou de saúde são ocupados por mulheres presas, é o que aponta o relatório final do Grupo de Trabalho Interministerial de Reorganização e Reformulação do Sistema Prisional Feminino (RAMOS, 2015). A permanência dessas mulheres em ambientes impróprios pode gerar conflitos e levá-las ao adoecimento. (CHESKYS, 2013).

Nos presídios femininos, além das violações supracitadas, existe também um controle da sexualidade, em muitas situações as mulheres são obrigadas a utilizar métodos contraceptivos, retirando delas o direito de decidirem pela maternidade e, quando essas mulheres ficam grávidas a maioria das unidades não tem estrutura adequada para o puerpério, a lactação e a convivência com os filhos. Apenas $34 \%$ dos estabelecimentos femininos possuem um espaço destinado às gestantes e no caso dos estabelecimentos mistos esse número cai para apenas 6\% (DEPEN, 2014). Além disso, a administração impõe a comprovação de matrimônio como condição para o recebimento de visita íntima e a proíbe a existência de relacionamento amoroso e sexual entre as detentas.

A partir disso, é visível que o tratamento prisional não se mostra sensível às questões de gênero, existindo uma discriminação ainda maior para com as mulheres presas, tendo em vista que elas fugiram do padrão de mulher doce, passiva, delicada, que é o que a sociedade espera delas. Daí elas recebem punição reforçada tanto do sistema carcerário como da 
sociedade ao serem destinadas a elas péssimas condições de encarceramento, maior isolamento pelo número reduzido de visitas que costumam receber, dificuldade de acesso a itens de higiene e aos serviços de saúde, privação ou reduzida atividade sexual, entre outras coisas (BREITMAN, 1999; CHESKIS, 2013).

$\mathrm{Na}$ unidade feminina visitada para as mulheres terem acesso a produtos de higiene, elas dependem de que a família leve nos dias de visita, as que não recebem visita, prestam serviço às demais para receber esses produtos em troca. Estas têm direito a visita íntima, porém, não há um espaço adequado para isso, sendo realizadas de improviso nas celas, demandando a saída das outras do espaço até que a visita termine. Além disso, segundo relato delas, a visita deveria durar de nove ao meio dia, tendo três horas de duração, mas a demora dos procedimentos de revista e falta de local adequado fazem com que tenha apenas uma hora de duração. Outra evidência da falta de adequação das penitenciárias ao gênero feminino que foi percebida na unidade visitada é a inexistência de espaço para gestantes, lactantes ou mulheres com filhos.

É possível perceber que as dificuldades para as mulheres vão além daquelas que atingem os homens e uma situação comumente vivenciada por mulheres presas é o afastamento familiar, que ocorre por diversos motivos. As revistas vexatórias, que ocorrem, sem exceção, para idosos ou crianças. A localidade das unidades prisionais, que muitas vezes se localizam distante dos grandes centros urbanos, tornando difícil o acesso da família, seja pela distância ou pela falta de recursos financeiros para custear o deslocamento. Por fim, ocorre também a ocupação da família com o cuidado dos filhos que essas mães não podem mais cuidar.

\section{PERFIL DA MULHER PRESA NO RIO GRANDE DO NORTE}

Apesar dos homens representarem a maioria da população carcerária, o número de mulheres presas vem aumentando substancialmente no Brasil. O Ministério da Justiça indica que, nos últimos doze anos, houve um aumento em $256 \%$ neste número, o que representa mais de trinta e seis mil mulheres presas, que corresponde a $7 \%$ da população carcerária (DEPEN, 2014). Dentre as possíveis justificativas para o crescimento da criminalidade feminina, podemos citar dificuldades financeiras que podem decorrer da baixa remuneração, da maior responsabilidade da mulher como provedora do lar atualmente; dinheiro fácil 
proporcionado pelo tráfico de drogas; uma necessidade de se manter dentro dos padrões consumistas da sociedade; influência de pessoas próximas como filhos e companheiros (CHESKYS, 2013; LIMA apud ESTEVAM, 2013).

De acordo com os dados do Depen de Junho de 2014, o perfil das mulheres presas é predominantemente de jovens de 18 a 29 anos, negras, onde a maior parte estudou até o ensino fundamental, mas não concluíram, são solteiras e, em sua maioria, tem de 1 a 7 filhos. Diante desses dados, Rita (2007) defende que a criminalidade está intimamente ligada ao grau de exclusão social da mulher, além de que a prisão reflete um cenário de desigualdade social, em que grupos mais vulneráveis acabam sendo punidos, como é o caso das mulheres.

Esse perfil também corrobora a tese de Wacquant (2001), que defende que, com o advento do capitalismo, o Estado promove a exclusão de pessoas, pobres, que não tem acesso ao mercado de consumo. Essas pessoas, tendo de sobreviver de alguma maneira, utilizam-se do mercado informal ou crime. Assim, há uma tendência à diminuição do Estado social, que garante direitos e um aumento de um Estado penal, que pune as pessoas excluídas do mercado de consumo, o que reflete no aumento da criminalidade e encarceramento. Outra questão que podemos refletir sobre esse perfil é a seletividade de justiça penal, já que condenações e punições sobre os crimes não são aplicados de forma igualitária, estão mais presentes sobre certos tipos de crime e sobre as classes sociais baixas (idem).

Verificou-se que 54\% das entrevistadas são adultas jovens (entre 20 e 29 anos) 40\% tinha entre 30 e 39 anos e $6 \%$ tinha entre 40 e 49 anos. Sobre a etnia, $49 \%$ se declararam pardas, $23 \%$ brancas, $17 \%$ pretas, $7 \%$ amarelas e $4 \%$ indígena. Sobre o estado civil, $72 \%$ eram solteiras, $28 \%$ eram casadas ou mantinham união estável. No que se refere a escolaridade, $63 \%$ estudaram até o ensino fundamental, $32 \%$ até o ensino médio e $5 \%$ até o ensino superior. Das entrevistadas, $24 \%$ não trabalhavam antes do aprisionamento, $76 \%$ trabalhavam, porém, exerciam ocupações de baixa remuneração, como diarista, empregada doméstica, feirante, manicure, garçonete, vendedora de catálogos, sendo que 85\% não tinham registro na carteira de trabalho e 15\% tinham. Quanto à renda familiar, 38\% das entrevistadas contavam com menos que um salário mínimo, 35\% um salário mínimo, $21 \%$ dois salários e $6 \%$ três salários.

No que diz respeito ao aspecto do suporte social, contrariando alguns dados literários, foi verificado que, dentre as entrevistadas, $46 \%$ recebem visita social, normalmente, realizada pelas mães e apenas $14 \%$ recebem visita íntima de seus companheiros, com uma frequência semanal a maioria. Levanta-se a hipótese de que o número de visitas familiares é 
relativamente alto pelo fato de que o presídio fica localizado numa região de fácil acesso na cidade. A literatura aponta um abandono dos companheiros às esposas presas, isso costuma ocorrer por uma questão cultural de atribuição do espaço social do crime ao gênero masculino. Normalmente, as mulheres encarceradas são logo abandonadas por seus companheiros e maridos, seja pelo estigma social da mulher que comete um delito ou em razão dos companheiros estabeleceram novas relações afetivas com maior rapidez (OLIVEIRA \& SANTOS, 2012).

No que se refere a assistência jurídica, $69 \%$ das entrevistadas afirmaram ter este tipo de assistência e $31 \%$ relataram que não. Dentre as que recebiam assistência, $40 \%$ era assistida por advogado, $30 \%$ por defensor público e $30 \%$ não especificou o tipo. Através desses dados, é notável que apesar da assistência jurídica ser um direito assegurado pela Lei de Execução Penal, na realidade ele ainda não é efetivado.

Sobre o âmbito das ações e serviços de saúde, o acesso dessa população é legalmente definido pela Constituição Federal de 1988, pela Lei n. ${ }^{\circ}$ 8.080, de 1990, que regulamenta o Sistema Único de Saúde, pela Lei de Execução Penal n. ${ }^{\circ}$ 7.210, de 1984 e pela Portaria Interministerial n. ${ }^{\circ}$ 1.777, de 2003, que instituiu o Plano Nacional de Saúde no Sistema Penitenciário, este prevê a inclusão da população penitenciária no SUS, garantindo que o direito à cidadania se efetive na perspectiva dos direitos humanos.

Apesar da já existência de todas essas leis, no ano de 2014 surge uma Política Nacional de Atenção Integral à Saúde das Pessoas Privadas de Liberdade no Sistema Prisional (PNAISP), Entre os objetivos da PNAISP está assegurar que cada unidade prisional, que custodia acima de cem presos, seja um ponto integrante da Rede de Atenção à Saúde do SUS.

Entretanto, no estado do Rio Grande do Norte, quase $80 \%$ das unidades prisionais não possuem módulos de saúde, existem apenas sete enfermeiros, quatorze técnicos de enfermagem, quatro médicos, um odontólogo, um técnico de odontologia e um psiquiatra para todas as unidades prisionais do estado, além disso, não há nenhum profissional de ginecologia e obstetrícia. Esses dados constam no relatório do Infopen de Junho de 2014, mas esse documento não deixa claro onde estão distribuídos esses profissionais.

Sobre o acesso aos serviços de saúde, $49 \%$ das entrevistadas informaram ter feito exames ginecológicos nos últimos meses, sendo eles realizados por uma enfermeira que vem até a unidade ou foram executados sob as mesmas condições em outras unidades, 30\% receberam atendimento médico, $4 \%$ odontológico e nenhuma delas recebeu atendimento psiquiátrico. Vale ressaltar que à exceção dos exames ginecológicos, nenhum desses 
atendimentos foram recebidos na unidade feminina pesquisada, elas foram atendidas por esses profissionais em outras unidades em que estiveram anteriormente, por este motivo relataram dificuldade em ter acesso aos serviços de saúde.

As mulheres em privação de liberdade são mais vulneráveis a doenças crônicas como o câncer de colo do útero e das mamas, assim como também a doenças sexualmente transmissíveis, especialmente a Aids, que tem maior incidência neste grupo do que na população geral, a sífilis e a tuberculose também afetam essas mulheres. (RAMOS, 2015). De acordo com os dados do Sistema de Informação de Agravos e Notificação (SINAN), que recebe informações de doenças de notificação compulsória, tem-se, hoje, dentre as mulheres encarceradas, 1204 que estão contaminadas por doenças transmissíveis, o que equivale a 5,3\% da população prisional feminina (nesses dados não consta a população do estado de São Paulo, pois o mesmo não forneceu tais informações).

\section{PERFIL PENAL E LEI DE DROGAS}

De acordo com os dados do DEPEN, a maioria das mulheres presas no Brasil foi condenada ou aguarda julgamento, primeiramente, por algum crime ligado ao tráfico de drogas, correspondendo a $68 \%$ das mulheres. Embora a maior incidência de crimes cometidos por mulheres seja esse, elas na maioria das vezes não desempenham um lugar de liderança e ocupam posição secundária a dos homens, que em algumas circunstâncias as usam para se protegerem. (FERRARI, 2010, p. 1330). Os crimes contra o patrimônio, como furto e roubo, também levam muitas mulheres para o cárcere e ocupam o segundo (representando 8\%) e terceiro lugar (representando 7\%), respectivamente, nas causas de aprisionamento. Como já foi mencionado anteriormente, muitas estão presas por envolvimento afetivo ou familiar com homens que realizam alguma atividade criminosa, com isso elas se envolvem também no mundo do crime.

Pode-se supor uma divisão sexual do crime, na qual a ela são destinadas as tarefas de providenciar e pagar um advogado, frequentar as delegacias como forma de pressão e frequentar as prisões, suprindo o homem de certas comodidades, tais como comida, dinheiro, drogas, contato e afeto. Em suma, ela é responsável pela manutenção de uma estrutura externa de preservação, bem como da garantia de um espaço de legalidade (BREITMAN, 1999, p. 218). 
Em relação ao perfil penal, esta pesquisa corrobora com os dados supracitados, destaca-se que $78 \%$ das entrevistadas foram presas por tráfico de drogas, $9 \%$ por assalto, $2 \%$ por homicídio, $2 \%$ por peculato e $2 \%$ por latrocínio. Em relação a quantidade de droga portada no momento da prisão, algumas entrevistadas declararam portar uma pequena quantidade. I.C.J tinha um cigarro de maconha, C.N.N portava duas pedras de crack para consumo próprio, J.S.C estava com vinte e cinco gramas de maconha, A.C.S contou que foram encontradas nove pedras de crack em frente à sua casa, A.C.L e M.M.L portavam cinco gramas de cocaína, C.L.A relatou que não tinha nenhuma droga e sua prisão "'foi forjada" (sic), entre outros exemplos. Diante desses dados, considera-se necessário problematizar a atual Lei de drogas do nosso país.

A Lei 11.343, que entrou em vigor em 2006, visava trazer avanços como a diferenciação entre traficante e usuário, abrandamento penal do usuário e reconhecimento para as políticas de prevenção e redução de danos. Apesar disto, esta Lei trouxe um efeito inverso na prática, onde pesquisas do Ministério da Justiça apontam que de 2006 a 2013, houve um aumento de 339\% no número de presos por tráfico (D'AGOSTINO, 2015).

Segundo Campos (2013), os relatórios de pesquisas feitas pela SAL/Pensando o Direito/Ministério da Justiça (2009), NEV-USP (2011), Instituto Sou da Paz (2012) e ITTC/Pastoral Carcerária (2012) demonstram que, atualmente, muitas pessoas são apreendidas com uma pequena quantidade de drogas. Esse efeito ocorre porque para esta lei a classificação entre tráfico e porte para uso próprio vai depender de fatores como: a quantidade e natureza da substância, o local onde foi apreendida, as condições da apreensão, circunstâncias sociais e pessoais da pessoa detida e antecedentes criminais, não tendo nenhum parâmetro objetivo acerca da quantidade. (CAMPOS, 2013)

Conclui-se que a Lei 11.343 trouxe mais um obstáculo na condução da problemática do uso e mercado de drogas. Como ela não traz meios objetivos para distinguir o usuário do traficante, essa distinção fica a critério dos responsáveis pela prisão e condenação da pessoa detida. E, segundo Veríssimo, (2010, p.337)

tendo em conta a seletividade da ação policial - que classifica as pessoas, mais em função do que elas parecem ser, segundo um sistema classificatório estigmatizador que atravessa tanto a polícia quanto a sociedade englobante - somada à ambigüidade da Lei, que não estabelece nítidas fronteiras entre uso e tráfico, podemos dizer que, a despeito das novidades da Lei, continuam os policiais na rua escolhendo quem deve ou não deve (e quem pode ou não pode) ser preso, quase sempre agindo na informalidade que, não raro, se configura através de ações violentas. 
Diante da lacuna da Nova Lei de Drogas para diferenciar, objetivamente, o usuário do traficante de drogas, o Instituto Garapé (2015), lançou uma nota técnica que objetivou produzir três cenários de quantidade de droga para a presunção de posse. Esses cenários foram construídos baseando-se em opiniões de profissionais das áreas médica, jurídica e político-criminal, da área médico-científica e usuários de drogas, levantados com o método Delphi. Além disso, utilizaram como referência legislações de países como Áustria, Espanha, Portugal e Uruguai. Os autores desta nota indicam que dos três cenários construídos, a quantidade mais adequada para a realidade brasileira estaria entre os cenários 2 e 3, conforme demonstra a tabela abaixo:

Tabela 01 - Quantidades de porte de drogas para consumo próprio - Cenários de Referência (consumo per capita)

\begin{tabular}{llll}
\hline Substâncias & Cenário 1 & Cenário 2 & Cenário 3 \\
\hline Maconha (gramas) & $25 \mathrm{~g}$ & $40 \mathrm{~g}$ & $100 \mathrm{~g}$ \\
\hline Maconha (pés fêmeas florindo) & 6 pés & 10 pés & 20 pés \\
\hline Cocaína/Crack (gramas) & $10 \mathrm{~g}$ & $12 \mathrm{~g}$ & $15 \mathrm{~g}$ \\
\hline
\end{tabular}

Fonte: Instituto Igarapé

Se essa nota for utilizada como parâmetro para a distinção entre porte de substâncias e tráfico de drogas, percebe-se que $33 \%$ das mulheres entrevistadas que foram presas por tráfico de drogas, poderiam ser classificadas como usuárias, pois declararam no questionário portar uma quantidade de entorpecentes que se encaixa entre o cenário 2 e 3.

A Comissão Global sobre Políticas de Drogas foi instituída pela ONU com o objetivo de trazer uma nova abordagem a essa problemática, trazendo o argumento de que a guerra às drogas não pode ser vencida e que outras medidas, a exemplo a descriminalização que ocorreu em alguns países, tiveram melhores resultados. Esta comissão é formada por ex-presidentes latino-americanos, Fernando Henrique Cardoso, do Brasil, César Gaviria, da Colômbia e Ernesto Zedillo, do México, além de outros líderes mundiais, sendo ao todo dezenove personalidades.

Em Junho de 2011, foi divulgado o relatório desta Comissão. Entre suas recomendações está a legalização e regulamentação da maconha, o fim da criminalização dos usuários de todas as drogas e o tratamento dos dependentes como pacientes e não como criminosos. O relatório alerta que a questão das drogas deve ser tratada como um problema de saúde pública, ao invés de ser alvo de criminalização e repressão policial, devendo os investimentos governamentais utilizados para repressão serem destinados a saúde. 
Essa abordagem de repressão aos consumidores dificulta a efetivação de medidas de saúde pública direcionas à redução dos danos causados pelo uso de drogas sobre os indivíduos, como as infecções por HIV/AIDS, as mortes por overdose, entre outras. Aponta, ainda, que países que ofereceram tratamento aos dependentes, ao invés de punição, tiveram resultados positivos na redução do crime, na melhoria das condições de saúde e na redução da dependência.

\section{SAÚDE MENTAL DAS MULHERES PRESAS}

Dados estatísticos revelam que a prevalência de transtornos mentais entre a população prisional é de $42 \%$, sendo maior que o da comunidade em geral, que é de $15 \%$, porém, na população feminina encarcerada, esse índice é ainda maior, pois $66 \%$ precisam de tratamento psiquiátrico e cerca de $20 \%$ faz ou já fez uso de medicação psicotrópica (RAMOS, 2015; CORDEIRO E MORANA, 2014). Dentre os transtornos e sofrimentos mentais pode-se destacar a depressão e outros que se relacionam ao uso de substâncias psicoativas, além disso, essa população também apresenta um risco aumentado de suicídio (idem).

É sabido que ambientes confinados são propiciadores de adoecimentos psicossociais, diante disso, seria importante que os profissionais que atuam nesse cenário tivessem um olhar mais atento para a identificação de possíveis transtornos mentais (RAMOS, 2015)

Verificou-se através da entrevista realizada neste estudo, que não há atendimento psiquiátrico na unidade já referida, apesar disso, $47 \%$ das mulheres que ali estão encarceradas utilizam psicotrópicos, sendo a maioria deles ansiolíticos e antidepressivos que chegam até elas por intermédio da família. Somente uma das entrevistadas disse receber a medicação da administração do presídio e já demonstrava sua preocupação com a situação.

Eu tive uma crise semana passada e o SAMU veio me atender aqui, por isso que eles estão me dando meu remédio, depois vou ter que fazer favor pras menina pra poder continuar tomando, minha família não vem me visitar, mas o problema é que esse remédio precisa de receita. (A.C.S.B. 39 anos).

Diante desses dados, compreende-se que, na unidade pesquisada, não se consolidou o Plano Nacional de Saúde no Sistema Prisional Feminino, pois foi visto que estas mulheres não são assistidas através dos serviços garantidos pelo SUS e nem tampouco tem seus direitos de cidadãs, na perspectiva dos direitos humanos, garantidos. 
No momento em que foi realizada a pergunta sobre a prestação de atendimento psiquiátrico, foi unânime a resposta da não existência desse serviço. Apesar disso, 47\% responderam que faziam uso de medicação psicotrópica, porém, não tinham suas doses ajustadas desde que chegaram ao presídio e percebiam sua saúde prejudicada diante da ausência de tal atendimento.

Alguns relatos demonstraram sofrimento psíquico diante do contexto de aprisionamento. Sendo assim, relacionam o uso da medicação psicotrópica a uma forma de aliviarem as dores do cárcere, a solidão, angústia, como pode ser também, uma forma delas manterem-se sob controle. De acordo com Foucault, nesse contexto a medicação seria um operador de poder, uma estratégia de assujeitamento para aquelas mulheres (FOUCAULT, 1999 apud IGNACIO e NARDI, 2007).

Essas mulheres têm seus corpos dominados, disciplinados pelo poder estatal. O poder disciplinar utiliza como ferramentas a punição e a vigilância, sendo estes os principais mecanismos para adestrar e docilizar o sujeito, pois é a partir deles que haverá a adequação às normas estabelecidas nas instituições como um processo de produção que, a partir de uma "tecnologia" disciplinar do corpo, construirá um sujeito com utilidade e docilidade (DINIZ \& OLIVEIRA, 2014)

\section{CONSIDERAÇÕES FINAIS}

Impossível, nos limites desse artigo, abarcar a complexa realidade da mulher presa no Rio Grande do Norte, assim pretendeu-se apenas delinear o perfil dessas mulheres e explorar os aspectos sócio familiares, jurídicos e de saúde. O artigo trouxe uma discussão teórica sobre algumas vivências daquelas mulheres, como o afastamento do convívio familiar, ruptura dos papéis sociais, visita social restrita, visita íntima realizada em local inapropriado e dificultada pela comprovação de união, controle da sexualidade, discriminação de gênero diante do crime e punição moral, falta de estrutura adequada ao gênero, inexistência de atendimento médico-odontológico, não fornecimento de medicações necessárias à continuidade de tratamentos médicos e nem mesmo medicações que não exigem receita médica, a exemplo de remédios para dores ou cólicas.

Após delinear o perfil da mulher presa no $\mathrm{RN}$ foram escolhidos dois eixos para nortear a escrita desse artigo, foram eles: perfil penal e Lei de Drogas e Saúde Mental da 
Mulher Presa, esses foram os temas que emergiram com mais força diante da exposição das mulheres durante a aplicação do questionário.

Julgou-se importante discutir a Lei 11.343, pois ficou claro que ela não trouxe nenhum avanço para o país, na forma de lidar com as questões de uso de drogas e tráfico. $\mathrm{O}$ presente trabalho corrobora com a literatura quando se diz que hoje existem muitas usuárias de drogas presas, cumprindo pena pelo crime de tráfico.

Quanto à saúde mental, também confirmamos o que a literatura traz, o número de mulheres presas sofrendo de agravos mentais é muito maior quando fazemos uma relação entre elas e as mulheres não privadas de liberdade de uma maneira geral. Foi perceptível na unidade visitada que não há cuidado em relação a esses agravos, as apenadas não têm continuidade ao atendimento psiquiátrico que recebiam antes da imposição da pena, com isso ficam utilizando por tempo prolongado medicações que foram prescritas antes do aprisionamento, o acesso a essas medicações para as mulheres daquela unidade só se dá por via familiar, demostrando que o Estado não assume tal responsabilidade.

Diante de tal cenário, onde ocorrem inúmeras violações de direitos humanos, assim como descumprimento das políticas destinadas às pessoas privadas de liberdade e da Lei de Execução Penal, percebe-se a total desresponsabilização do Estado no que diz respeito à garantia dos direitos mínimos dessas mulheres. Torna-se necessário e urgente a fiscalização da efetivação das políticas já existentes que são voltadas para esse público.

\section{REFERÊNCIAS}

BRASIL. Constituição (1984). Lei nº 7210, de 11 de julho de 1984. Lei de Execução Penal. Brasília, DF, Disponível em: <http://www.planalto.gov.br/ccivil_03/LEIS/L7210.htm>. Acesso em: 07 out. 2015.

Ministério da Justiça. Levantamento Nacional de informações penitenciárias. INFOPEN MULHERES-junho2014. Disponível em: < Disponível em: < http://www.justica.gov.br/noticias/estudo-traca-perfil-da-populacao-penitenciaria-femininano-brasil/relatorio-infopen-mulheres.pdf>. Acesso em: 04 ab. 2016. 
Ministério Da Justiça e Cidadania - Governo Federal. Número de mulheres presas aumentou 256\% em 12 anos. Disponível em: <http://www.justica.gov.br/noticias/numerode-mulheres-presas-aumentou-256-em-12-anos>. Acesso em: 18 out. 2015.

Ministério da Saúde. Plano Nacional de Saúde no Sistema Penitenciário. Disponível em: http://bvsms.saude.gov.br/bvs/publicacoes/cartilha_pnssp.pdf. Acesso em: 27. ab. 2016.

- Ministério da Saúde. Sistema de Informação de Agravos de Notificação. Disponível em:http://sinan.saude.gov.br/sinan. Acesso em: 10. ab. 2016.

BREITMAN, Miriam Rodrigues. Criminalidade feminina: outra versão dos papéis da mulher. Revista Sociologias, Dossiê conflitualidade, ano $1 \mathrm{n}^{\mathrm{o}} 1$ jan/jun. 1999. Porto Alegre, PPGS Programa de Pós-Graduação em Sociologia da Universidade Federal do Rio Grande do Sul/UFRGS.

CAMPOS, Marcelo da Silveira. Drogas, políticas e encarceramento no Brasil. Disponível em: <http://www.bancodeinjusticas.org.br/drogas-politicas-e-encarceramento-no-brasil/> . Acesso em: 03 mar. 2016.

CORDEIRO, Quirino; MORANA, Hilda Clotilde Penteado. Saúde mental da mulher presa. Physichiatry on line Brasil. Vol.19, N 02, Fev. 2014.Disponível em: <http://www.polbr.med.br/ano14/for0214.php>. Acesso em: 09 nov. 2015.

CHESKYS, Débora. Aprisionando mulheres - uma análise da influência dos estereótipos de gênero na execução de políticas públicas para mulheres encarceradas. In: SEMINÁRIO INTERNACIONAL FAZENDO GÊNERO, 10, 2013, Florianópolis. Anais Eletrônicos. Florianópolis: Universidade Federal de Santa Catarina, 2013. p. 1 - 12.

D'AGOSTINO, Rosanne. Com Lei de Drogas, presos por tráfico passam de 31 mil para 138 mil no país. G1. 24 Julho. 2015. Disponível em: <http://g1.globo.com/politica/noticia/2015/06/com-lei-de-drogas-presos-por-trafico-passamde-31-mil-para-138-mil-no-pais.html> . Acesso em: 20 fev. 2016. 
DINIZ, Francisco Rômulo Alves; OLIVEIRA, Almeida Alves de Oliveira. Foucault: do poder disciplinar ao biopoder. Scientia, Vila Velha-ES, v. 2, n. 3 - Nov. 2013/Jun. 2014. Semestral.

FERRARI, Ilka Franco. Mulheres encarceradas: elas, seus filhos e nossas políticas. Revista Mal-estar e Subjetividade, Fortaleza, v. 10, n. 4, p.1325-1352, dez. 2010. Mensal.

FOUCAULT, Michel. Conferência IV. In: FOUCAULT, Michel. A Verdade e as Formas Jurídicas. 3. ed. Rio de Janeiro: Nau Editora, 2002. Cap. 4. p. 79-103.

GOFFMAN, E. Manicômios, prisões e conventos. Tradução de Dante Moreira Leite. São Paulo: Perspectiva, 1974.

IGNACIO, Vivian Tatiana Galvão; NARDI, Henrique Caetano. A medicalização como estratégia biopolítica: um estudo sobre o consumo de psicofármacos no contexto de um pequeno município do Rio Grande do Sul. Psicologia \& Sociedade, Porto Alegre, RS, v. 3, n. 19, p.88-95, set. 2007. Quadrimestral.

INSTITUTO IGARAPÉ (São Paulo) (Ed.). Nota técnica: critérios objetivos de distinção entre usuários e traficantes de drogas. 2015. Disponível em: <http://jota.uol.com.br/notatecnica-criterios-objetivos-de-distincao-entre-usuarios-e-traficantes-de-drogas>. Acesso em: 20 fev. 2016.

LAKATOS, Eva Maria. Fundamentos de metodologia científica. Marina de Andrade Marconi, Eva Maria Lakatos. - 5. ed. - São Paulo: Atlas 2003.

OLIVEIRA, Magali Gláucia Fávaro de; SANTOS, André Filipe Pereira Reid dos. Desigualdade de gênero no sistema prisional: considerações acerca das barreiras à realização de visitas e visitas íntimas às mulheres encarceradas. Caderno Espaço Feminino, Uberlândia-MG, v. 25, n. 1 - Jan/Jun. 2012. Semestral. 
RAMOS, Pe. Almir José de (Org.). Saúde da mulher presa. Pastoral Carcerária. 12 de nov. 2015. Disponível em: <http://carceraria.org.br/e-a-saude-da-mulher-presa-comovai.html>. Acesso em: 09 nov. 2015.

RITA, Rosangela Peixoto Santa. Mães e crianças atrás das grades: em questão o princípio da dignidade da pessoa humana. 2007. Dissertação (Mestrado) - Curso de Política Social, Departamento de Serviço Social, Universidade de Brasília, Brasília, 2007.

RN, Governo do Estado do. Secretaria de Estado da Justiça e Cidadania. Disponível em: <http://www.sejuc.rn.gov.br/>. Acesso em: 02 out. 2015.

VERÍSSIMO, Marcos. A nova lei de drogas e seus dilemas: Apontamentos para o estudo das formas de desigualdade presentes nos interstícios do ordenamento jurídico-penal brasileiro. Civitas, Porto Alegre, v. 10, n. 2, p.330-344, maio-ago. 2010.

WACQUANT, Loïc. 2001. As prisões da miséria. Tradução Ed André Telles. Rio de Janeiro: Jorge Zahar, p.176.

THE REALITY OF THE IMPRISONED WOMAN IN THE STATE OF RIO GRANDE DO NORTE

\begin{abstract}
Public policies aimed at female incarceration are fragile and barely seen in practice. Before that, it was aimed to investigate the reality of the imprisoned women in the state of Rio Grande do Norte. Therefore, their social and penal profile, the health conditions they are submitted to and the legal aspects were outlined. Women who are in custody at a State's penitentiary were used as a sample for this research, with whom a questionnaire was applied. Forty-three women participated, most of them young adults, brown-skinned, single, who studied up to elementary school, worked before their imprisonment and received low income. Most of them had already been sentenced, were not recidivists and had legal assistance, prevailing the crime of drug dealing. Besides that, the participants reported not having medical, dental, gynecological or psychiatric assistance. The only care with their health consists in the Papanicolaou test, made by a nurse.
\end{abstract}


Keywords: Imprisoned woman. Mental health. Drug Law. 